MANCHESTER

1824

넌

Economics

Discussion Paper Series

EDP-1015

\title{
Mixed oligopoly, vertical product differentiation and fixed quality- dependent costs
}

Stefan Lutz

Mario Pezzino

July 2010

Economics

School of Social Sciences

The University of Manchester

Manchester M13 9PL 


\title{
Mixed oligopoly, vertical product differentiation and fixed quality-dependent costs ${ }^{\dagger}$
}

\author{
Stefan Lutz ${ }^{*}$ and Mario Pezzino**
}

A private and a public firm face fixed quality-dependent costs of production and compete first in quality and then either in prices or in quantities. In the long run the public firm targets welfare maximization whereas the private firm maximizes profits. In the short run both firms compete in prices or quantities to maximize profits.

Mixed competition is always socially desirable compared to a private duopoly regardless of the type of competition in the short run and the equilibrium quality ranking. In addition, mixed competition seems to be a more efficient regulatory instrument than the adoption of a minimum quality standard.

JEL classification: L13, L33, L50, H44

Keywords: vertical product differentiation, mixed oligopoly, quality, price and quantity competition

\footnotetext{
${ }^{\dagger}$ The views expressed in this paper are solely those of the authors and do not necessarily reflect those of the institutions they are affiliated with. We are grateful for support provided by the International Centre for Economic Research (ICER), Torino, Italy, and by the Spanish Minstry of Education and Science (Grant No. ECO2008-06191). We also would like to thank Joanna Poyago-Theotoky and Iñigo Herguera for helpful discussions and suggestions. "University of Manchester, School of Social Sciences. Manchester, M13 9PL. Email: stefan.lutz@manchester.ac.uk, Tel.: +49 173576 4013, Fax: +49 1802119912111.

${ }^{* *}$ University of Manchester, School of Social Sciences. Manchester, M13 9PL.

Email: mario.pezzino@manchester.ac.uk, Tel.: +44 161275 1383, Fax: +44 1612754812.
} 


\section{Introduction}

With the term "mixed oligopolies" the literature refers to competition among firms that have different objective functions ${ }^{1}$. Examples of mixed oligopolies are offered by sectors such as telecommunications, postal services, banking, education, health care.

Competition between private and public firms has been the objective of study of various previous contributions. These include studies that considered homogenous product mixed oligopolies ${ }^{2}$ as well as models of mixed oligopoly with product differentiation ${ }^{3}$.

Grilo (1994) is, to our knowledge, the first work that studied duopolistic mixed competition when products are vertically differentiated and firms choose non-cooperatively first qualities and then prices. Under the assumptions of fully covered markets and variable quality-dependent costs, using the Mussa and Rosen (1978)'s utility function, the author shows that the presence of a public welfare maximizing firm can lead to the social optimum ${ }^{4}$ (described in terms of qualities and market share distribution). The assumption of covered market and inelastic demand produces the result that the public firm does not need to deal with any distortion associated with non-optimal consumption due to firms' market power and consequently the mixed duopoly can be socially optimal.

Delbono et al. (1996), using a model similar to Grilo (1994), introduce the possibility that the market might be uncovered (implying that a mixed duopoly can not reach the social optimum). The authors show that there exist two equally plausible equilibria in which either firm can be the high quality provider ${ }^{5}$. In addition they show that in equilibrium both firms always price above marginal costs. In fact, any time the private competitor prices above marginal costs, the public firm would choose a price higher than marginal cost in order to avoid to serve too many (from a social point of view) consumers. Finally, it is shown that the presence of the public firm in the market decreases quality differences and increases market coverage and welfare.

\footnotetext{
${ }^{1}$ In general the literature assumes that public firms target social welfare maximization. See Anderson et al. (1997) for a defence of this assumption.

${ }^{2}$ A common feature of these contributions is that firms are assumed to compete in quantities and that it is always socially optimal to nationalize all firms in the market. See Merrill and Schneider (1966), De Fraja and Delbono (1989), Cremer et al. (1989).

${ }^{3}$ Cremer et al. (1991) study price competition in a market represented by a Hotelling (1929) line in which private and public firms choose first locations and then prices.

4 As pointed out in Delbono et al. (1996)), the result reported in Grilo (1994) should not be particularly surprising: as shown in Cremer and Thisse (1991) a model of pure vertical differentiation with covered market and variable quality-dependent costs where firms select first qualities and then prices corresponds to a Hotelling (1979) model in which firms choose first locations and then prices. In other words, Grilo (1994) produces a result already described in Cremer et al. (1991).

${ }^{5}$ They also show that if the public firm had a Stackelberg advantage on quality selection, it would provide the high quality in equilibrium.
} 
Another example of mixed oligopoly with vertical differentiation and uncovered markets is provided by Jofre-Bonnet (2000). The author uses Motta (1994)'s rendition of the model in Sutton (1991), with fixed quality-dependent costs. With in mind competition among health care providers ${ }^{6}$, it is assumed that a public provider would aim patients' surplus under the constraint of universal coverage, a budget constraint and breakeven of the private providers' profits. The author shows that mixed oligopoly may be the least expensive and the most satisfactory scenario for patients when compared to pure private provision and a public monopoly.

The objective of our model is to study the social desirability of a mixed duopoly with vertical product differentiation in a model à la Mussa and Rosen (1978) when firms face fixed quality-dependent costs and the market is uncovered. The assumption that quality-dependent costs are fixed implies that quality is enhanced mainly by investments in $\mathrm{R} \& \mathrm{D}$ (rather than the selection or better raw materials or more skilled labour). Such an assumption implies that for a given pair of qualities a welfare maximizing firm competing in the short run in prices (or in quantities) with a profit maximizing rival would try to leave the whole market to be served by the high quality provider (regardless its ownership). Intuitively, since quality costs do not increase with the volume of consumers served, a welfare maximizing firm prefers all consumers to buy the high quality.

In the model described in this paper we consider an alternative possibility: in the long run the public firm selects quality in order to maximize social welfare, but in the short run the same firm chooses prices (or quantities) to maximize profits. Such an assumption allows us to study a more interesting scenario in which the market is served by both firms in equilibrium and some consumers (those with a low willingness to pay for quality) would not buy any good. The type of public firm we are going to consider can describe rather realistically the behaviour of a state-owned firm that has the statutory mission to maximize welfare (for example through quality provision), but in the short run is managed by independent profit maximizing agents ${ }^{7}$. A public hospital in which quality selection (mostly in the hands of medical staff) follows welfare maximization, while price (or quantity) decisions are in the hands of profitoriented managers could be an example of the public firm we are going to describe in this paper. ${ }^{8}$

\footnotetext{
${ }^{6}$ Barros and Martinez-Giralt (2002) is another example of mixed duopoly in which hospitals choose qualities (facing fixed quality-dependent costs) and prices (under different reimbursement systems). The model is however an extension of a Hotelling (1979) model in which all patients have the same willingness to pay for quality.

${ }^{7}$ The analysis of principal-agent issues or the firm internal bargaining are out of the scope of this paper.

${ }^{8}$ Empirical contributions on hospital competition, for example, show that the short run competitive behaviour of non-profit and public hospitals does not differ significantly from the behaviour of the profit maximizing rivals. See Pauly (1987), Dranove et al. (1986), Becker and Sloan (1985), Sloan (2000).
} 
The paper shows that social welfare is always higher under mixed duopoly, regardless the type of short run competition and the ranking of equilibrium qualities. ${ }^{9}$ In addition, when the public firm is the low quality provider in equilibrium, it selects a level of quality that coincides with an endogenous minimum quality standard ${ }^{10}$. As shown in previous contributions in the literature, the introduction of an exogenous minimum quality standard (i.e. a standard that introduces a binding constraint on the lower quality in the market) in a private duopoly with product differentiation and fixed qualitydependent costs is desirable ${ }^{11}$ under Bertrand competition, but harmful if firms compete in quantities ${ }^{12}$ in the short run (restricting the feasible quality space, the introduction of a standard has a negative effect on both firms' profits that more than offsets the increase in consumer surplus). The policy implication of this result is that mixed competition can be a more efficient regulatory instrument when compared with the introduction of a minimum quality standard when firms compete in quantities ${ }^{13}$ in the short run. As we are going to show in this paper, under Cournot competition the presence of a public provider decreases the equilibrium low quality (regardless which firm provides it); in other words, the presence of a public firm produces an opposite result (and therefore socially desirable) compared with a minimum quality standard.

Another interesting result is that welfare is always higher when in equilibrium the public firm provides the higher quality. The result seems to suggest that (at least in those markets in which firms require quality certification to be recognized as high quality providers) the regulation of a private duopoly would be more efficient if implemented through the introduction of instruments that increase the high quality rather than through minimum quality standards.

The specific effects of the presence of a public provider and the social desirability of partial privatization depend however on the type of short run competition and the ranking of equilibrium qualities. The model, indeed, produces two possible equilibria (whether the public firm is the high or low quality provider). Similarly to the result in Delbono et al. (1996), both firms would prefer to be the high quality provider and therefore both equilibria are equally plausible. In addition, only when the public firm serves the low quality segment of the market under Cournot competition, numerical simulations

\footnotetext{
${ }^{9}$ This result is also supported by empirical research, e.g. for the transport industry. While mixed competition does not recover the socially optimal solution, the presence of a public firm is a useful measure to get closer to the social optimum. See, e.g., Campos and Cantos Sanchez (2004) and Cantos Sachez and Moner-Colonques (2006).

${ }^{10}$ See Ecchia and Lambertini (1997).

${ }^{11}$ See Ronnen (1991).

${ }^{12}$ See Valletti (2000).

${ }^{13}$ Under Cournot competition an exogenous quality standard would decrease welfare and an endogenous quality standard would simply be ineffective since the quality constraint would not be binding.
} 
show that partial privatization could be socially desirable; otherwise, full nationalization of the public firm is the most efficient solution.

In order to concentrate on a clearer derivation of the main results presented in this paper, the chosen modelling abstracts from some important factors such as asymmetric information as well as rent-seeking activities by individual agents and groups within public and/or private firms. Addressing these important issues is left for further research.

The remainder of the paper is organized as follows. Section 2 recalls the equilibria of the private duopoly under Bertrand and under Cournot short run competition. Section 3 describes the mixed duopoly under Bertrand and under Cournot short run competition, distinguishing and comparing the cases in which the public firm is the high or low quality provider in equilibrium. Section 4 compares the equilibria under private and mixed competition and considers the possibility to partially privatize the public firm. Section 5 concludes.

\section{The private duopoly}

Two identical firms simultaneously compete in qualities in stage one and in prices (or quantities) in stage two. Costs are fixed (quadratic and identical for the two firms) and quality-dependent.

We look for Subgame Perfect Nash Equilibria by the method of backward induction. Specifically, the model presents the following assumptions:

- $\quad$ Two identical firms sell the same good, differentiated only by quality; let $s_{i} \in \mathfrak{R}_{+}, q_{i} \in \mathfrak{R}_{+}$and $p_{i} \in \mathfrak{R}_{+}$represent respectively the quality, the quantity and the price offered by firm $i$, where $i=1,2$.

- $\quad$ Let us suppose that firm 1 is a private firm whereas firm 2 is a state-owned firm. In stage two each firm's problem is to maximize its own profit function: $\Pi_{i}\left(q_{i}, s_{i}\right)=p_{i} q_{i}-F_{i}, i=1,2$. The quality-dependent cost functions are given by: $F_{i}=\left(s_{i}\right)^{2} / 2$. In stage one, instead, the public firm selects quality in order to maximize social welfare; firm 1 maximizes profits again.

- A unit mass of consumers are in the market; each consumer wants to buy at most one unit of the good; consumers differ only on their willingness to pay for quality, represented by the parameter $t \in[0,1]$, uniformly distributed on its support with density equal to one.

The surplus of consumer $k$, with value of quality $t_{k}$, who buys one unit of the good produced by firm $i$ at price $p_{i}$ and quality $s_{i}$ is given by: $U_{k}^{i}=t_{k} s_{i}-p_{i}$. 
Motta (1993) describes private duopolistic competition with vertically differentiated goods and uncovered markets under Bertrand or Cournot competition. Being the equilibria symmetrical, either of the two firms can be the low or the high quality provider. In lemma 1 firm $h=1,2$ is the high quality provider and firm $l=1,2, l \neq h$ is the low quality provider; moreover $C S=\int_{t_{h}}^{1}\left(t s_{h}-p_{h}\right) d t+\int_{t_{l}}^{t_{h}}\left(t s_{l}-p_{l}\right) d t \quad$ and $\quad W=C S+\Pi_{1}+\Pi_{2} \quad$ represent respectively consumer surplus and social welfare, and $t_{h}=\left(p_{h}-p_{l}\right) /\left(s_{h}-s_{l}\right)$ and $t_{l}=p_{l} / s_{l}$ are the willingness to pay for quality respectively of the consumer indifferent to buy from either provider and of the consumer indifferent to buy from the low quality provider or not to buy at all.

\section{Lemma 1}

If two identical firms face fixed quality-dependent costs and maximize profits selecting simultaneously and non cooperatively

(i) first qualities and then prices, in equilibrium:

$$
\begin{array}{cccccc}
s_{h}=0.2533 & s_{l}=0.0482 & p_{h}=0.1077 & p_{l}=0.0102 & q_{h}=0.5246 \quad q_{l}=0.2638 \\
\Pi_{h}=0.0244 & \Pi_{l}=0.0015 & C S=0.0432 & W=0.0691 & t_{h}=0.4754 & t_{l}=0.2116 ;
\end{array}
$$

(ii) first qualities and then quantities, in equilibrium:

$$
\begin{aligned}
& s_{h}=0.2519 s_{l}=0.0902 p_{h}=0.1136 p_{l}=0.0248 q_{h}=0.4508 q_{l}=0.2747 \\
& \Pi_{h}=0.0195 \Pi_{l}=0.0027 C S=0.0402 \mathrm{~W}=0.0624 t_{h}=0.5492 t_{l}=0.2745 \text {. }
\end{aligned}
$$

Lemma 1 shows that fiercer (Bertrand) competition in the short run produces in equilibrium lower prices, higher coverage, higher consumer surplus and total welfare. Another important result is that the type of competition in which firms are engaged in the short run has significant effects on their strategic behaviour with respect to quality. It can be shown that under Bertrand duopolistic competition ${ }^{14}$ qualities are strategic complements for both firms. Instead, under Cournot competition ${ }^{15}$, qualities are strategic complements for the high quality firm and strategic substitutes for the low quality firm.

\footnotetext{
${ }^{14}$ See Ronnen (1991) and Lutz and Pezzino (2009).

${ }^{15}$ See for example Valletti (2000), Herguera et al. (2002), Jinji (2003) and Poyago-Theotoky (2003).
} 


\section{Mixed duopoly}

Let us now consider the possibility that one of the two firms (namely firm 2) in stage 1 selects quality to maximize welfare. We shall consider first the case in which firms compete in prices in the short run.

\subsection{Bertrand mixed competition}

Under Bertrand competition in the short run, equilibrium prices ${ }^{16}$ are given by:

$$
p_{h}=\frac{2 s_{h}\left(s_{h}-s_{l}\right)}{4 s_{h}-s_{l}} \quad p_{l}=\frac{s_{l}\left(s_{h}-s_{l}\right)}{4 s_{h}-s_{l}}
$$

It follows that in stage one profits and consumer surplus are given by:

$$
\begin{gathered}
\Pi_{h}=\frac{4 s_{h}^{2}\left(s_{h}-s_{l}\right)}{\left(s_{l}-4 s_{h}\right)^{2}}-\frac{s_{h}^{2}}{2} \quad \Pi_{l}=\frac{s_{h} s_{l}\left(s_{h}-s_{l}\right)}{\left(s_{l}-4 s_{h}\right)^{2}}-\frac{s_{l}^{2}}{2} \\
C S=\frac{s_{h}^{2}\left(4 s_{h}+5 s_{l}\right)}{2\left(s_{l}-4 s_{h}\right)^{2}}
\end{gathered}
$$

Given that in stage one the two firms have different objective functions we need to distinguish the cases when the public firm is the low or high quality provider.

\subsubsection{Public firm is the low quality provider (e.g. $\left.s_{l}=s_{h}, s_{2}=s_{l}\right)$}

Firms' profits are in this case equal to $\Pi_{1}=\Pi_{h}$ and $\Pi_{2}=\Pi_{l}$ as reported in (2) ; the objective function of firm 2 is given by $W$.

The first order conditions for maximization of respectively $\Pi_{1}$ and $W$ are given by:

$$
\begin{aligned}
& \frac{\partial \Pi_{1}}{\partial s_{1}}=\frac{4\left(4 s_{1}^{2}-3 s_{1} s_{2}+2 s_{2}^{2}\right)}{\left(4 s_{1}-s_{2}\right)^{3}}-s_{1}=0 \\
& \frac{\partial W}{\partial s_{2}}=\frac{s_{1}^{2}\left(20 s_{1}-17 s_{2}\right)}{2\left(4 s_{1}-s_{2}\right)^{3}}-s_{2}=0
\end{aligned}
$$

and the simultaneous satisfaction gives the equilibrium qualities:

$$
s_{1}=0.2779 \quad s_{2}=0.1352
$$

\footnotetext{
${ }^{16}$ See Motta (1993).
} 
Note that, defining $R_{i}=p_{i} q_{i}$, marginal revenues increase if the rival's quality increases (i.e. $\partial^{2} R_{i} / \partial s_{i} \partial s_{j}>0, i=1,2, j \neq i$ ) and profit functions are concave (i.e. $\partial^{2} \Pi_{i} / \partial s_{i}^{2}<0, \quad i=1,2$ ). In addition, $\partial^{2} C S / \partial s_{i}^{2}>0, \quad i=1,2$ $\partial^{2} C S / \partial s_{1} \partial s_{2}>0, \partial^{2} R_{1} / \partial s_{2}^{2}<0$ and $\partial^{2} W / \partial s_{2}^{2}<0$. It can be shown that no firm has the incentive to leapfrog the rival (notice in addition the objective function of the public firm does not depend on the ranking of the qualities provided).

The slope of the quality best response functions of the two firms are given (totally differentiating the first order conditions) by:

$$
\begin{gathered}
\frac{d s_{1}}{d s_{2}}=-\frac{\frac{\partial^{2} R_{1}}{\partial s_{1} \partial s_{2}}}{\frac{\partial^{2} \Pi_{1}}{\partial s_{1}^{2}}}>0 \\
\frac{d s_{2}}{d s_{1}}=-\frac{\frac{\partial^{2} C S}{\partial s_{1} \partial s_{2}}+\frac{\partial^{2} R_{1}}{\partial s_{1} \partial s_{2}}+\frac{\partial^{2} R_{2}}{\partial s_{1} \partial s_{2}}}{\frac{\partial^{2} C S}{\partial s_{2}^{2}}+\frac{\partial^{2} R_{1}}{\partial s_{2}^{2}}+\frac{\partial^{2} \Pi_{2}}{\partial s_{2}^{2}}}
\end{gathered}
$$

It can be shown that the numerator and the denominator of expression (7) are respectively positive and negative, implying that the slope of the quality best response functions of both firms is positively sloped and that qualities are strategic complements for both firms.

The strategic behaviour of the private firm is standard: since its marginal revenues increase with respect to the public firm's quality, in order to increase the level of product differentiation and relax price competition, firm 1 is always willing to increase its quality (and incur higher costs). The public firm strategically behaves in a similar way; the intuition is that an increase in the quality of the private firm has a positive effect both on marginal revenues and marginal consumer surplus, inducing the public firm to invest more in quality. Given the assumptions of the model and the expression in (7), we can already expect that the strategic behaviour of both firms would not change inverting the equilibrium quality ranking (i.e. $s_{2}>s_{1}$ ).

Table 1 reports the equilibrium values of the main variables of the model when the public firm is the low quality provider and firms compete in prices in the short run. 


\begin{tabular}{cccccc}
\hline$s_{1}=0.2779$ & $s_{2}=0.1352$ & $p_{1}=0.0812$ & $p_{2}=0.0198$ & $q_{1}=0.5692$ & $q_{2}=0.2846$ \\
\hline$\Pi_{1}=0.0076$ & $\Pi_{2}=-0.0035$ & $C S=0.0724$ & $W=0.0765$ & $t_{1}=0.4308$ & $t_{2}=0.1462$ \\
\hline
\end{tabular}

Table 1: mixed duopoly equilibrium when $s_{1}>s_{2}$ under Bertrand competition

The values reported in table 1 will be discussed and compared to the private duopoly in section 4. Notice however that in this case, even if mixed competition increases welfare and market coverage ${ }^{17}$, the public firm earns negative profits in equilibrium. The result should not be surprising if we consider that when the public firm is the low quality provider under Bertrand competition it selects the same quality of a regulator setting a minimum quality standard to maximize welfare ${ }^{18}$. Since unregulated qualities are both socially insufficient, a regulator can impose a standard sufficiently high to let both firms (given the strategic complementarity of qualities) provide higher qualities. However, since the regulator can affect directly only the low quality, the standard will push the low quality provider to incur a loss at the standard that maximizes welfare.

\subsubsection{Public firm is the high quality provider (e.g. $\left.s_{1}=s_{l}, s_{2}=s_{h}\right)$}

Firms' profits are in this case equal to $\Pi_{1}=\Pi_{l}$ and $\Pi_{2}=\Pi_{h}$ as reported in (2) ; the objective function of firm 2 is again given by $W$.

The first order conditions for maximization of respectively $\Pi_{1}$ and $W$ are given by:

$$
\begin{aligned}
& \frac{\partial \Pi_{1}}{\partial s_{1}}=\frac{s_{2}^{2}\left(4 s_{2}-7 s_{1}\right)}{\left(4 s_{2}-s_{1}\right)^{3}}-s_{1}=0 \\
& \frac{\partial W}{\partial s_{2}}=\frac{s_{2}\left(88 s_{2}^{2}-66 s_{1} s_{2}+17 s_{1}^{2}\right)}{\left(4 s_{2}-s_{1}\right)^{3}}-1-s_{2}=0
\end{aligned}
$$

and the simultaneous satisfaction of them gives the equilibrium qualities ${ }^{19}$ :

$$
s_{1}=0.0525 \quad s_{2}=0.3752
$$

Given that the marginal revenues of both firms are increasing in the quality selected by the rival and that marginal consumer surplus is increasing in both

\footnotetext{
${ }^{17}$ Similarly to the case described in Delbono et al. (1996).

${ }^{18}$ See Ronnen (1991) and Ecchia and Lambertini (1997).

${ }^{19}$ It can be shown again that no firm deviates from the equilibrium leapfrogging the quality chosen by the rival.
} 
qualities, it follows that qualities are again strategic complements as in the case described above in section 3.1.1.

Table 2 reports the equilibrium values of the main variables of the model when the public firm is the high quality provider in equilibrium.

\begin{tabular}{llllll}
\hline$s_{1}=0.0525$ & $s_{2}=0.3752$ & $p_{1}=0.0117$ & $p_{2}=0.1672$ & $q_{1}=0.2590$ & $q_{2}=0.5181$ \\
\hline$\Pi_{1}=0.0017$ & $\Pi_{2}=0.0162$ & $C S=0.0592$ & $W=0.0771$ & $t_{1}=0.2228$ & $t_{2}=0.4819$ \\
\hline
\end{tabular}

Table 2: mixed duopoly equilibrium when $s_{2}>s_{1}$ under Bertrand competition

The degree of product differentiation increases (firms increase the provision of high quality and decrease the provision of low quality), consumer surplus decreases and a smaller number of consumers is served in equilibrium. However, since both firms earn higher profits, total welfare increases.

\subsection{Cournot mixed competition}

Under Cournot competition in the short run, equilibrium prices ${ }^{20}$ are given by:

$$
p_{h}=\frac{s_{h}\left(2 s_{h}-s_{l}\right)}{4 s_{h}-s_{l}} \quad p_{l}=\frac{s_{h} s_{l}}{4 s_{h}-s_{l}}
$$

It follows that in stage one profits and consumer surplus are given by:

$$
\begin{gathered}
\Pi_{h}=\frac{s_{h}\left(s_{l}-2 s_{h}\right)}{\left(s_{l}-4 s_{h}\right)^{2}}-\frac{s_{h}^{2}}{2} \quad \Pi_{l}=\frac{s_{h}^{2} s_{l}}{\left(s_{l}-4 s_{h}\right)^{2}}-\frac{s_{l}^{2}}{2} \\
C S=\frac{s_{h}\left(4 s_{h}^{2}+s_{h} s_{l}-s_{l}^{2}\right)}{2\left(s_{l}-4 s_{h}\right)^{2}}
\end{gathered}
$$

Given that in stage one the two firms have different objective functions we need again to distinguish the cases when the public (welfare maximizing) firm is the low or high quality provider.

\footnotetext{
${ }^{20}$ See again Motta (1993).
} 


\subsubsection{Public firm is the low quality provider (e.g. $\left.s_{l}=s_{h}, s_{2}=s_{l}\right)$}

Firms' profits are equal to $\Pi_{1}=\Pi_{h}$ and $\Pi_{2}=\Pi_{l}$ as reported in (11); the objective function of firm 2 is given by $W$.

The first order conditions for maximization of respectively $\Pi_{1}$ and $W$ are given by:

$$
\begin{aligned}
& \frac{\partial \Pi_{1}}{\partial s_{1}}=\frac{\left(2 s_{1}-s_{2}\right)\left(8 s_{h}^{2}-2 s_{h} s_{l}+s_{l}^{2}\right)}{\left(4 s_{1}-s_{2}\right)^{3}}-s_{1}=0 \\
& \frac{\partial W}{\partial s_{2}}=\frac{s_{1}^{2}\left(4 s_{1}+3 s_{2}\right)}{2\left(4 s_{1}-s_{2}\right)^{3}}-s_{2}=0
\end{aligned}
$$

and the simultaneous satisfaction of them gives the equilibrium qualities:

$$
s_{1}=0.2504 \quad s_{2}=0.0394
$$

Profit functions are concave (i.e. $\left.\partial^{2} \Pi_{i} / \partial s_{i}^{2}<0, i=1,2\right)$ and, in contrast to the case in which firms compete in prices, now marginal revenues are increasing in the rival's quality only for the high quality firm (i.e. $\left.\partial^{2} R_{1} / \partial s_{1} \partial s_{2}>0, \quad \partial^{2} R_{2} / \partial s_{1} \partial s_{2}<0\right)$. This implies that firm 2's quality is still a strategic complement ${ }^{21}$ for firm 1 ; however firm 1 's quality is now a strategic substitute for firm 2. Specifically, the numerator of expression (7) is now negative. Being Cournot competition less fierce than price competition, the literature $^{22}$ has already pointed out that the rival's quality is a strategic substitute for the (private) low quality firm since its marginal revenues decrease if the high quality increases. This will be the explanation of the strategic quality behaviour of the private firm described in the next subsection. Interestingly, the fact that firms compete in quantities in the short run modifies the strategic quality behaviour of the low quality firm, if public. It follows that in the equilibrium in which the public firm is the low quality provider the slope of both firms' reaction function is negative.

The public firm takes into consideration the negative effect of an increase in high quality on the low quality firm's marginal revenues. In addition, the effect on marginal consumer surplus (still increasing in both qualities) is not sufficiently high to justify a strategic increase in quality.

Table 3 reports the equilibrium values of the main variables of the model when the public firm is the low quality provider.

\footnotetext{
${ }^{21}$ The expressions of the slope of the quality best response functions are given again by (6) and (7).

${ }^{22}$ See Jingi (2002), Valletti (2000).
} 


\begin{tabular}{cccccc}
\hline$s_{1}=0.2504$ & $s_{2}=0.0394$ & $p_{1}=0.1201$ & $p_{2}=0.0103$ & $q_{1}=0.4795$ & $q_{2}=0.2602$ \\
\hline$\Pi_{1}=0.0262$ & $\Pi_{2}=0.0019$ & $C S=0.0350$ & $W=0.0632$ & $t_{1}=0.5205$ & $t_{2}=0.2602$ \\
& & & & & \\
\hline
\end{tabular}

Table 3: mixed duopoly equilibrium when $s_{1}>s_{2}$ under Cournot competition

The similarity between the behaviour of a public firm and the adoption of a minimum quality standard described in section 3.1.1 can not be found now that firms compete in the short run in quantities. As shown by Valletti (2000) in a similar setting ${ }^{23}$ the adoption of a binding minimum quality standard has a negative effect on the profits of both firms that more than offsets the increase in consumer surplus (due to the increase in the provision of qualities). If the low quality firm is nationalized, instead, it would choose a quality lower than the one that would be chosen by an unregulated private firm, allowing both firms to earn higher profits and increasing social welfare ${ }^{24}$. In this sense, nationalization of one firm might be socially preferable (compared with an exogenous quality standard) and more effective (compared with an endogenous quality standard) than other forms of quality regulation.

If compared to the mixed duopolistic equilibrium shown in section 3.1.1, short run Cournot competition produces lower qualities, less coverage, lower consumer surplus and social optimum.

\subsubsection{Public firm is the high quality provider (e.g. $s_{1}=s_{l}, s_{2}=s_{h}$ )}

Firms' profits are in this case equal to $\Pi_{1}=\Pi_{l}$ and $\Pi_{2}=\Pi_{h}$ as reported in (11); the objective function of firm 2 is again given by $W$.

The first order conditions for maximization of respectively $\Pi_{1}$ and $W$ are given by:

$$
\begin{aligned}
& \frac{\partial \Pi_{1}}{\partial s_{1}}=\frac{s_{2}^{2}\left(4 s_{2}+s_{1}\right)}{\left(4 s_{2}-s_{1}\right)^{3}}-s_{1}=0 \\
& \frac{\partial W}{\partial s_{2}}=\frac{s_{2}\left(-8 s_{2}^{2}-6 s_{1} s_{2}-3 s_{1}^{2}\right)}{\left(4 s_{2}-s_{1}\right)^{3}}+\frac{1}{2}-s_{2}=0
\end{aligned}
$$

and the simultaneous satisfaction of them gives the equilibrium qualities ${ }^{25}$ :

\footnotetext{
${ }^{23}$ Pezzino (2010) shows that a minimum quality standard would be harmful also when a third firm enters the market.

${ }^{24}$ Note however that consumers would be worse off due to the presence of a low quality public provider.

${ }^{25}$ It can be shown again that no firm deviates from the equilibrium leapfrogging the quality of the rival.
} 


$$
s_{1}=0.0770 \quad s_{2}=0.3738
$$

As we said in the previous section, if the private firm is the low quality provider its marginal revenues decrease with respect to $s_{2}$; consequently, it treats the quality of the public firm as a strategic substitute $\left(d s_{1} / d s_{2}<0\right)$. In addition, the quality of the private firm is a strategic substitute (at least locally) for the public firm as well $\left(d s_{2} / d s_{1}<0\right)$.

Table 4 reports the equilibrium values of the main variables of the model when the public firm is the high quality provider in equilibrium.

\begin{tabular}{cccccc}
\hline$s_{1}=0.0770$ & $s_{2}=0.3738$ & $p_{1}=0.0203$ & $p_{2}=0.1768$ & $q_{1}=0.2636$ & $q_{2}=0.4728$ \\
\hline$\Pi_{1}=0.0024$ & $\Pi_{2}=0.0137$ & $C S=0.0541$ & $W=0.0702$ & $t_{1}=0.2636$ & $t_{2}=0.5272$ \\
\hline
\end{tabular}

Table 4: mixed duopoly equilibrium when $s_{2}>s_{1}$ under Cournot competition

If compared to the mixed duopolistic equilibrium shown in section 3.1.2, short run Cournot competition increases the high quality and decreases the low quality; in addition it produces less coverage, lower consumer surplus and social optimum.

\section{Comparisons}

Table 5 reports the equilibrium values of the main variables of the model under private/mixed duopoly under Bertrand or Cournot competition. Propositions 1 and 2 compare the equilibria under private and mixed duopoly.

\section{Proposition 1}

If firms compete in the short run in prices, under mixed competition compared to private duopoly:

i) if $s_{1}>s_{2}$ :

both qualities, market coverage, consumer surplus and social welfare are higher; profits instead are lower and in particular the public firm has a loss;

ii) if $s_{2}>s_{1}$ :

both qualities, the low quality provider's profits, consumer surplus and welfare are higher; the profits of the high quality provider and market coverage are lower instead. 


\begin{tabular}{ccc|cc|cc}
\hline \multicolumn{3}{c|}{ Private } & \multicolumn{4}{c}{ Mixed } \\
\hline \multicolumn{3}{c}{ Bertrand } & Cournot & \multicolumn{2}{c}{ Bertrand } & \multicolumn{2}{c}{ Cournot } \\
& & & $s_{1}>s_{2}$ & $s_{2}>s_{1}$ & $s_{1}>s_{2}$ & $s_{2}>s_{1}$ \\
$s_{1}$ & 0.2533 & 0.2519 & 0.2779 & 0.0525 & 0.2504 & 0.0770 \\
$s_{2}$ & 0.0482 & 0.0902 & 0.1352 & 0.3752 & 0.0394 & 0.3738 \\
$p_{1}$ & 0.1077 & 0.1136 & 0.0812 & 0.0117 & 0.1201 & 0.0203 \\
$p_{2}$ & 0.0102 & 0.0248 & 0.0198 & 0.1672 & 0.0103 & 0.1768 \\
$q_{1}$ & 0.5246 & 0.4508 & 0.5692 & 0.2590 & 0.4795 & 0.2636 \\
$q_{2}$ & 0.2638 & 0.2747 & 0.2846 & 0.5181 & 0.2602 & 0.4728 \\
$\Pi_{1}$ & 0.0244 & 0.0195 & 0.0076 & 0.0017 & 0.0262 & 0.0024 \\
$\Pi_{2}$ & 0.0015 & 0.0027 & -0.0035 & 0.0162 & 0.0019 & 0.0137 \\
$C S$ & 0.0432 & 0.0402 & 0.0724 & 0.0592 & 0.0350 & 0.0541 \\
$W$ & 0.0691 & 0.0624 & 0.0765 & 0.0771 & 0.0632 & 0.0702 \\
$t_{1}$ & 0.4754 & 0.5492 & 0.4308 & 0.2228 & 0.5205 & 0.2636 \\
$t_{2}$ & 0.2116 & 0.2745 & 0.1462 & 0.4819 & 0.2602 & 0.5272 \\
\hline
\end{tabular}

Table 5: equilibrium private and mixed duopoly. Under private duopoly, without loss of generality, it is assumed that firm 1 is the high quality provider.

\section{Proposition 2}

If firms compete in the short run in quantities, under mixed competition compared to private duopoly:

i) if $s_{1}>s_{2}$ :

both qualities, market coverage, consumer surplus and the profits of the low quality provider are lower; social welfare and the profits of the high quality provider are instead higher;

ii) if $s_{2}>s_{1}$ :

the quality selected and the number of consumers served by the high quality and the low quality provider are respectively higher and lower; profits are lower, market coverage, consumer surplus and welfare are higher.

Propositions 1 and 2 convey the message that mixed competition is always socially desirable regardless of the type of short run competition and equilibrium quality ranking.

However the way the presence of a public firm increases welfare differs in the various cases. Under Bertrand competition, for example, the public firm's behavior increases the efficiency of the system increasing quality competition and, consequently, consumer surplus. Profits, however, are lower than under private competition; if providing the low quality firm 2's profits are even negative (we described above the similarity between the quality selection of public firm and the selection of a benevolent regulator).

If firms compete in quantities in the short run, the way welfare increases with the nationalization of firm 2 varies even more. If firm 2 provides the low 
quality in equilibrium, then welfare is increased by an increase in firm 1's profits that more than offsets the decrease in consumer surplus (both qualities are lower under mixed competition ${ }^{26}$ ) and firm 2's profits. If, instead, firm 2 is the high quality provider, the high quality in equilibrium is higher than under private competition generating higher consumer surplus and welfare; both firms earn lower profits now.

Moreover, the degree of product differentiation always increases under Cournot competition; under Bertrand competition product differentiation decreases if $s_{1}>s_{2}$, otherwise (in contrast to the case shown in Delbono et al. (1996)) differentiation shows the greatest increase.

A possibility we have not considered so far is that the public firm might be only partially nationalized ${ }^{27}$. We suppose that the objective function of the public firm is given now by a combination of own profits and welfare. If $a \in[0,1]$, the new objective function of the public firm can be written as:

$$
S=\Pi_{2}+a\left(C S+\Pi_{1}\right)
$$

If $a=0$, then firm 2 is a profit maximizing agent and equilibria are described in lemma 1 . If instead $a=1$, firm 2 is welfare maximizing firm and its behaviour has been described in propositions 1 and 2 .

The results of numerical simulations (see appendix) describe the equilibrium values of qualities, profits, consumer surplus and welfare as functions of parameter $a$. Propositions 3 and 4 summarize the results.

\section{Proposition 3}

If firms choose first qualities and then prices, full nationalization (i.e. $a=1$ ) of the public firm produces the highest welfare, highest qualities and consumer surplus in equilibrium. Firms' profits decrease with a and $\Pi_{2}$ becomes negative for sufficiently high $a$.

The monotonicity with respect to $a$ of the relevant variables considered implies that the same comments regarding the result in proposition 1 apply to proposition 3 .

\footnotetext{
${ }^{26}$ As argued above, the quality selection of public firm in this case can not be compared to the introduction of a minimum quality standard.

${ }^{27}$ In a homogenous product quantity competition setting Matsumura (1998) shows that it is always preferable to partially privatized the public firm. Other works considering the possibility that the public firm's objective function is a (convex) combination of profits and welfare are Delbono and Scarpa (1995) and White (2002). De Donder and Roemer (2009) study instead the internal bargaining process inside a public firm managed by three groups of agents: (profit maximizing) owners, (revenue maximizing) managers and (welfare maximizing) government. The authors provide the results of numerical simulations that show that welfare may be increasing in the bargaining power of the government.
} 


\section{Proposition 4}

If firms choose first qualities and then quantities, full nationalization (i.e. $a=1)$ of the public firm produces the highest welfare and consumer surplus in equilibrium only if $s_{2}>s_{1} ; s_{2}$ and $s_{1}$ respectively increases and decreases; $\Pi_{1}$ monotonically decreases, while $\Pi_{2}$ initially increases and then decreases with a.

If $s_{1}>s_{2}$, both qualities, consumer surplus and $\Pi_{2}$ decrease with respect to $a$, while $\Pi_{1}$ increases. Social welfare is maximized for $0<a<1$.

The results in proposition 4 show that when firms compete in quantities in the short run quality ranking plays an important role. If $s_{2}>s_{1}$ then full nationalization is socially preferable (even if firms earn lower profits). If instead $s_{1}>s_{2}$, partial nationalization of firm 2 would be socially desirable. In particular, for low values of $a$ the high quality firm's profits increase with $a$ while $\Pi_{2}$ and consumer surplus decrease. It follows that initially the positive effect on $\Pi_{1}$ more than offsets the low in $C S$ and $\Pi_{2}$ until a critical value of $a$ (corresponding to the maximum welfare); for higher values of $a$ the negative effect on CS and $\Pi_{2}$ lowers total welfare.

\section{Conclusions}

The paper analyzed mixed competition between a public (welfare maximizing) firm and a private (profit maximizing) rival that face fixed quality-dependent costs and select non-cooperatively first qualities and then prices (or quantities). The paper shows that the nationalization of one of the two firms is always socially desirable, regardless the type of short run competition and the quality ranking in equilibrium.

The specific effects of the nationalization (or the social desirability of partial privatization of firm 2), however, depend on the degree of short run competition and whether the public firm is the high or low quality provider in equilibrium.

We have shown that welfare is always higher when firm 2 is the high quality provider. In fact, in this case under Bertrand competition, both qualities are higher than when $s_{1}>s_{2}$. It follows that the higher consumer surplus and firm 1's profits more than balance the decrease in $\Pi_{2}$. Nationalization of firm 2 produces similar effects under Cournot competition, except on the profits of firm 1 that in this case decrease as well.

The main message of the paper is that, whenever possible, nationalization of the low quality provider is more efficient than the introduction of a minimum quality standard. In addition, since welfare is always higher when the public firm is the high quality provider in equilibrium, it follows that policy 
instruments (e.g. quality certifications) that increase the unregulated high quality in a market served by two private firms are again socially preferable compared to minimum quality standards, regardless the type of competition in the short run.

Nevertheless, there remain significant other problems with mixed competition in practice arising in part from asymmetric information as well as principal-agent issues. In particular, rent-seeking activities by individual agents and groups within public firms, but also within private firms, may lead to additional inefficiencies. This may also explain the mixed record in industries such as the health sector or public transport. Therefore the modelling approach chosen in our paper was geared towards first establishing comparative welfare results in the absence of asymmetric information and principal-agent problems. Taking into account these important issues is left for further research.

\section{References}

Anderson, S., P., De Palma, A. and Thisse, J.-F. (1997): "Privatisation and Efficiency in a Differentiated Industry", European Economic Review, 41, 1635-1654.

Barros, P.P. e Martinez-Giralt, X. (2002): "Public and Private Provision of Health Care", Journal of Economics and Management Strategy, 11, pp. 109-33.

Becker, E.R. and Sloan, F.A. (1985): "Hospital ownership and performance", Economic Inquiry, 23, 21-36.

Campos, J. and Cantos Sanchez, P. (2004): "Regulating Privatized Rail Transport”, World Bank Policy research Working Paper, No. 2064.

Cantos Sanchez, P. and Moner-Colonques, R. (2006): "Mixed Oligopoly, Product Differentiation and Competition for Public Transport Services", Manchester School, 74(3), 294-313.

Cremer, H., Marchand, M. and Thisse, J-F. (1989): "The Public Firm as an Instrument for Regulating an Oligopolistic Market", Oxford Economic Papers, 41, 283-301.

Cremer, H., Marchand, M. and Thisse, J-F. (1991): "Mixed Oligopoly with Differentiated Products", International Journal of Industrial Organization, 9, 43-53. 
De Donder, P. and Roemer, J.E. (2009): "Mixed oligopoly equilibria when firms' objectives are endogenous", International Journal of Industrial Organization, 27, 414-423.

De Fraja, G. (1993): "Unions and wages in public and private firms: a game-theoretic analysis", Oxford Economic Papers 45, 457-469.

De Fraja, G. and Delbono, F. (1989): "Alternative Strategies of a Public Enterprise in Oligopoly", Oxford Economic Papers, 41, 302-311.

De Fraja, G. and Delbono, F. (1990): "Game Theoretic Models of Mixed Oligopoly", Journal of Economic Surveys, 4, 1-17.

Delbono, F., Denicolò, V., Scarpa, C. (1996): "Quality choice in a vertically differentiated mixed duopoly", Economic Notes, 25, 33-46.

Delbono, F. and Scarpa, C. (1995): "Upward-sloping reaction functions under quantity competition in mixed oligopolies", Bulletin of Economic Research, 47, 341-346.

Dranove, D., Satterthwaite, M. and Sindelar, J. (1986): "The "new competitiveness' in health care: some implications for price and quantity", Inquiry, 23, 429-431.

Ecchia, G., and Lambertini, L. (1997): "Minimum Quality Standards and Collusion", The Journal of Industrial Economics, 45, 101-113.

Grilo, I. (1994): "Mixed duopoly under vertical differentiation", Annales d'economie et de statistique, 33, 92-112.

Herguera, I., Kujal, P. and Petrakis, E. (2002): "Tariffs, Quality Reversals and Exit in Vertically Differentiated Industries", Journal of International Economics, 58, 467-492.

Hotelling, H. (1929): "Stability in Competition", The Economic Journal, $39,41-57$.

Jinji, N. (2003): "Strategic Policy for Product R\&D with Symmetric Costs", Canadian Journal of Economics, 36, 994-1006.

Jofre-Bonnet, M. (2000): "Health care: private and /or public provision", European Journal of Political Economy, 16, 469-489. 
Lutz, S. and Pezzino, M. (2009): "International strategic choice of minimum quality standards and welfare", ICER, Turin, working paper 02/2009.

Matsumura, T. (1998): "Partial Privatisation in Mixed Oligopoly", Journal of Public Economics, 70, 473-483.

Matsumura, T. (2003): "Stackelberg Mixed Duopoly with a Foreign Competitor", Bulletin of Economic Research, 55, 275-287.

Matsumura, T. and Kanda, O. (2005): "Mixed Oligopoly at Free Entry Markets", Journal of Economics, 84, 27-48.

Matsushima, N. and Matsumura, T. (2003-a): "Mixed Oligopoly with Product Differentiation: Sequential Choice of Location", Australian Economic Papers, 42, 18-34.

Matsushima, N. and Matsumura, T. (2003-b): "Mixed Oligopoly and Spatial Agglomeration”, Canadian Journal of Economics, 36, 62-87.

Matsushima, N. and Matsumura, T. (2004): "Endogenous Cost Differentials between Public and Private Enterprises: a Mixed Duopoly Approach", Economica, 71, 671-688.

Merrill, W. and Schneider, N. (1966): "Government Firms in Oligopoly Industries: A short run analysis”, Quarterly Journal of Economics, 80, 400412.

Motta, M. (1993): "Endogenous Quality Choice: Price Vs. Quantity Competition", Journal of Industrial Economics, 41, 113-131.

Motta, M. (1994): "International trade and investments in a vertically differentiated industry", International Journal of Industrial Organization, 12, 179-196.

Mussa, M. and Rosen, S. (1978): "Monopoly and Product Quality", Journal of Economic Theory, 18, 301-317.

Pauly , M.V. (1987): "Non-profit hospitals in medical markets", American Economic Review, 77, 257-262.

Pezzino, M. (2010): "Minimum Quality Standards with More than two firms under Cournot Competition", IUPJournal of Managerial Economics, Forthcoming. . 
Poyago-Theotoky, J. (2003): "Optimal Environmental Taxation, R\&D Subsidization and the Role of Market Conduct", Finnish Economic Papers, 16(1), 15-26.

Ronnen, U. (1991): "Minimum Quality Standards, Fixed Costs, and Competition", Rand Journal of Economics, 22, 490-504.

Scarpa, C. (1998): "Minimum Quality Standards with More Than Two Firms", International Journal of Industrial Organization, 16, 665-676.

Sloan, F.A. (2000): "Property rights in the hospital industry", in Frech, H.E. and Zeckauser, R. (eds), "Health care in America", San Francisco, Pacific Research Institute.

Sutton, J. (1991): "Sunk costs and market structure", MIT press.

Valletti, T., M. (2000): "Minimum Quality Standards under Cournot Competition", Journal of Regulatory Economics, 18, 235-245.

White, M. (2002): "Political manipulation of a public firm's objective function", Journal of Economic Behavior \& Organization, 49, 487-499.

\section{Appendix}

We report the results of numerical simulations ${ }^{28}$ reproducing equilibrium quality selection when the objective function of firm 2 is given by (17) and $a \in[0,1]$.

\footnotetext{
${ }^{28}$ Simulations, available by request, are performed with the software Mathematica.
} 


\section{A.1. Bertrand short run competition}

A.1.1. $s_{1}>s_{2}$

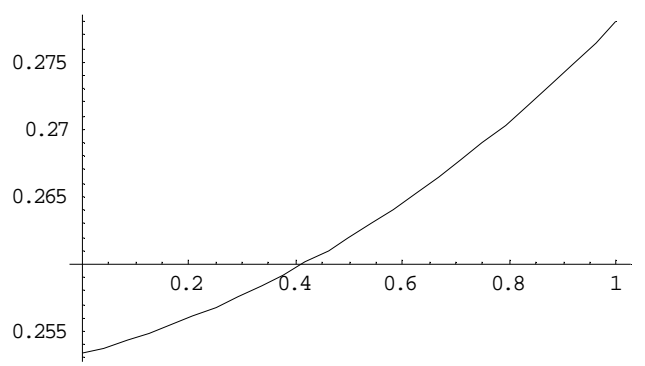

Figure 1: $s_{1}$

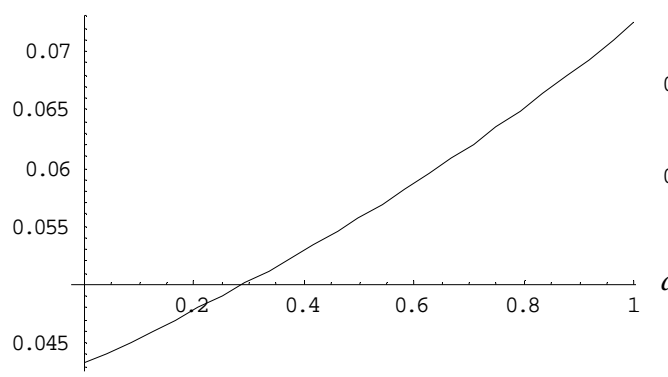

Figure 3: $C S$

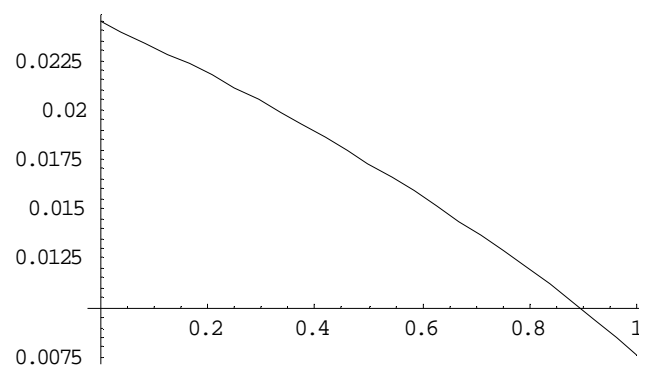

Figure 5: $\Pi_{h}$

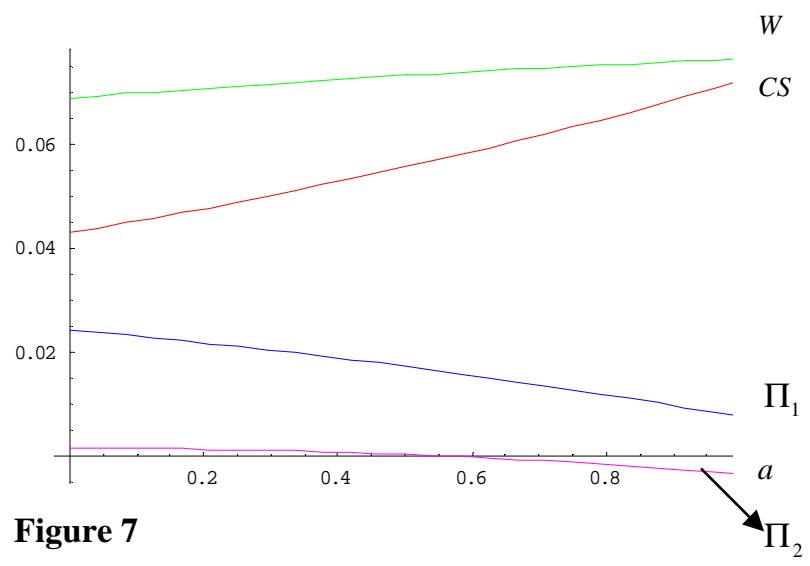

Figure 2: $s_{2}$

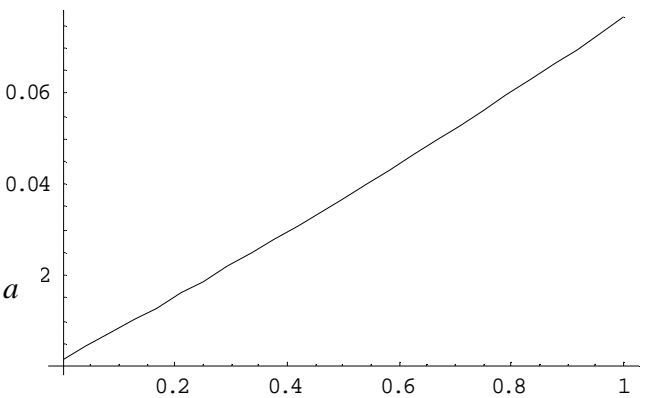

Figure 4: $W$

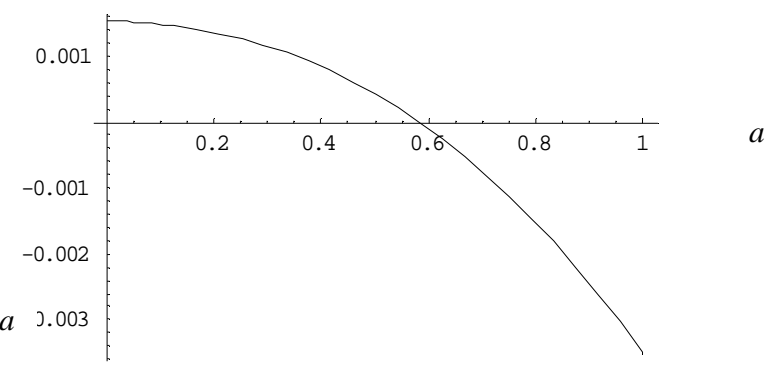

Figure 6: $\Pi_{l}$

W

$I_{1}$ 
A.1.2. $s_{2}>s_{1}$

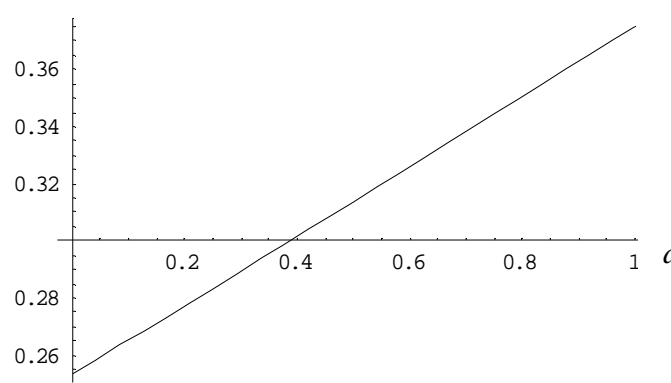

Figure 8: $s_{h}$

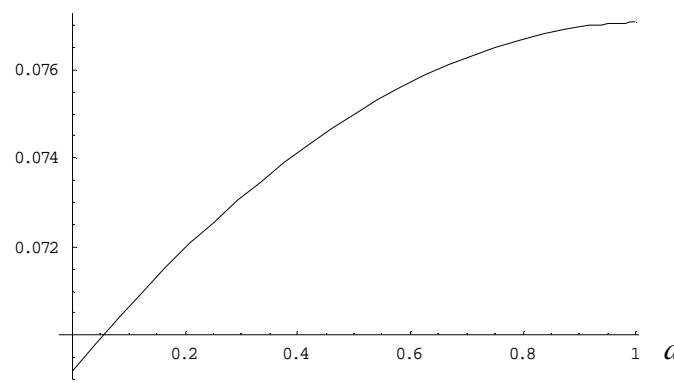

Figure 10: $W$

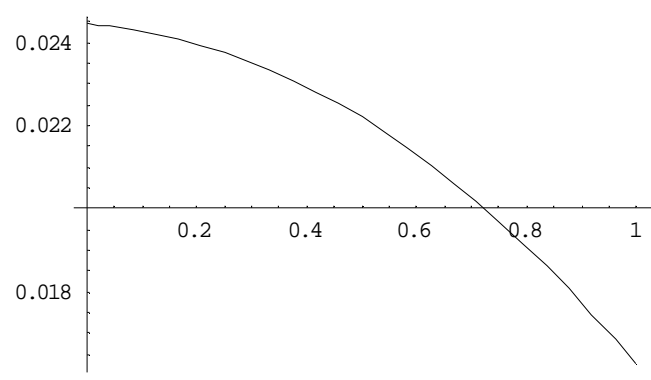

Figure 13: $\Pi_{h}$

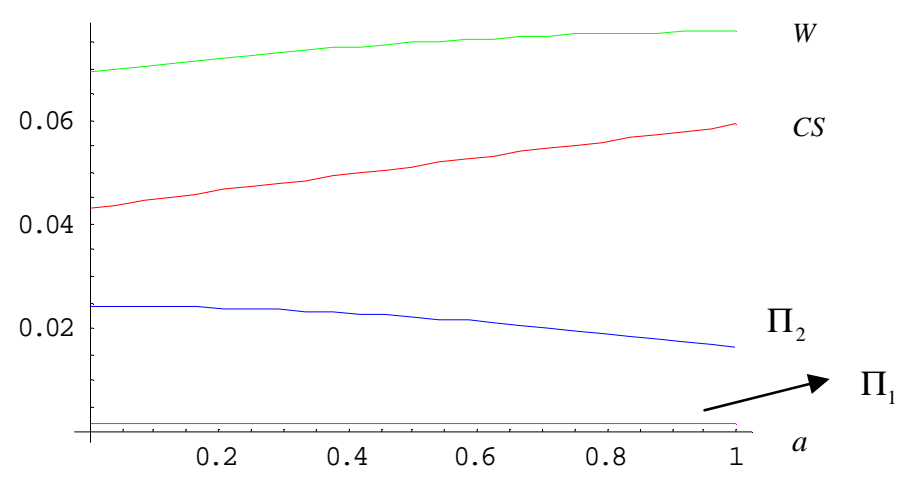

Figure 15

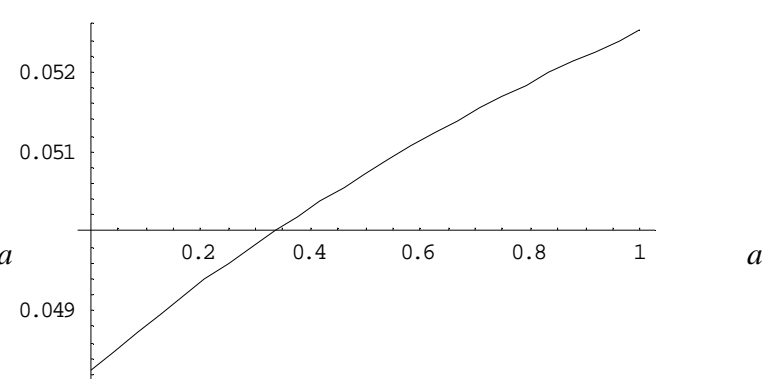

Figure 9: $s_{l}$

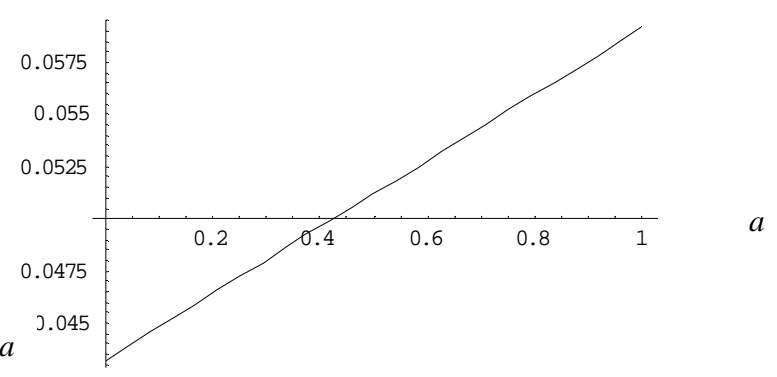

Figure 11: $C S$

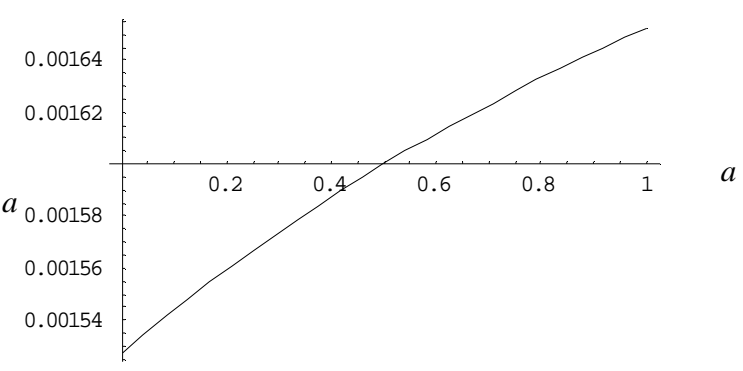

Figure 14: $\Pi_{l}$

W

CS

$\Pi_{1}$ 


\section{A.2. Cournot short run competition}

A.2.1. $s_{1}>s_{2}$

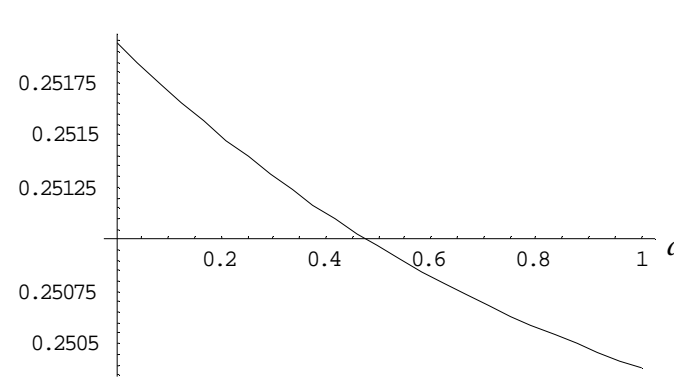

Figure 16: $s_{1}$

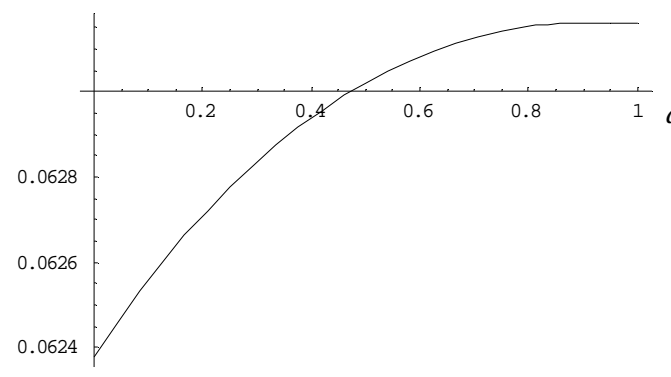

Figure 18: $W$

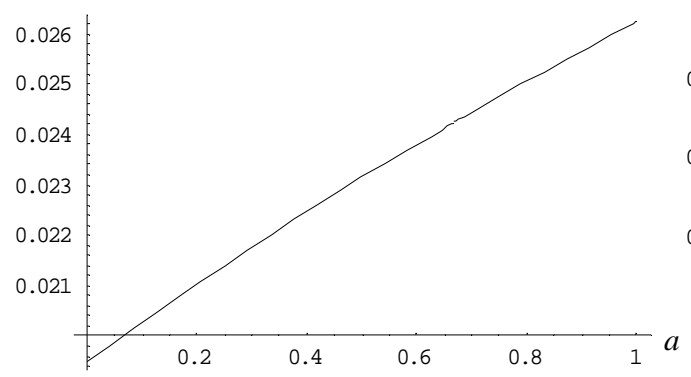

Figure 20: $\Pi_{1}$

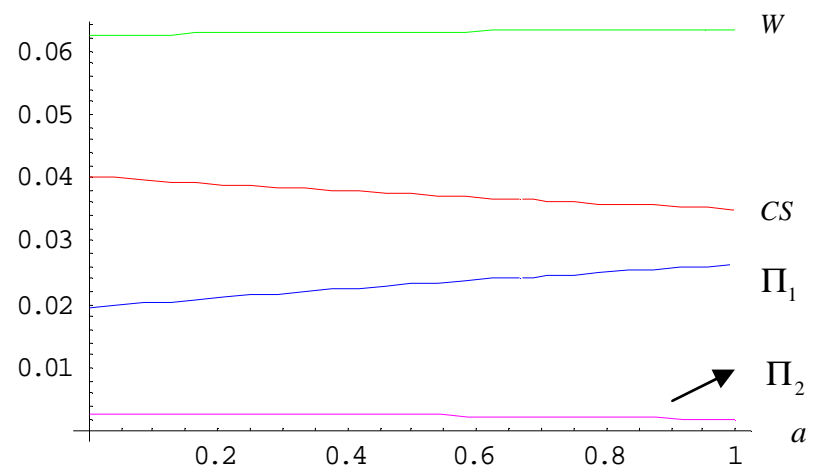

Figure 22

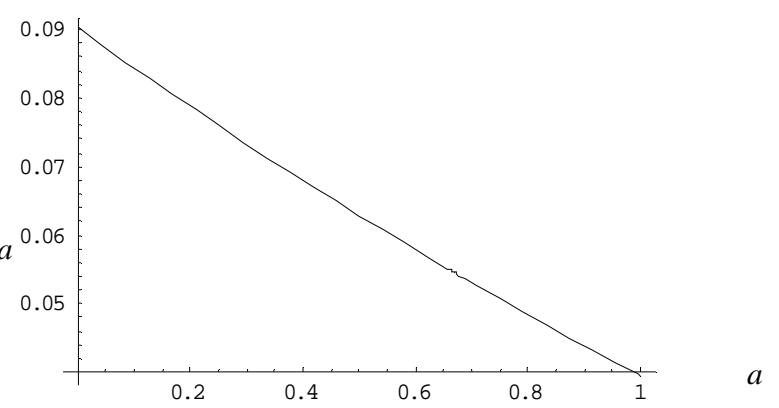

Figure 17: $s_{2}$

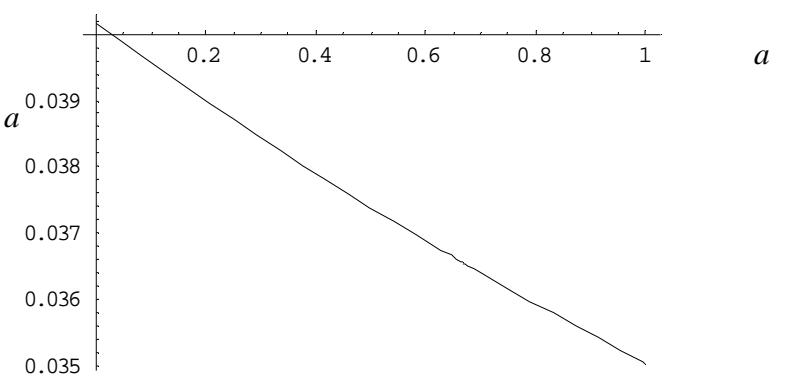

Figure 19: $C S$

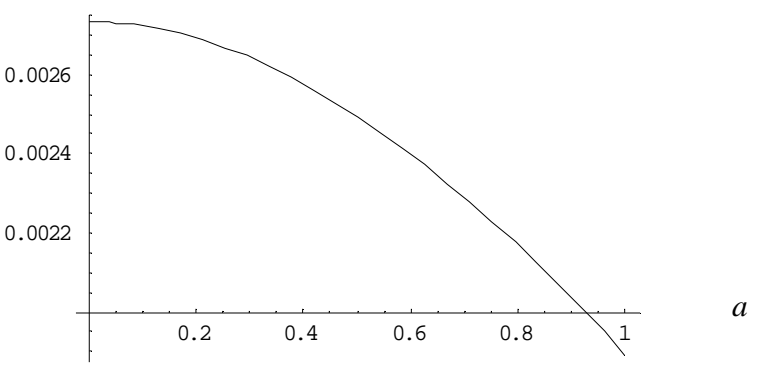

Figure 21: $\Pi_{2}$

W 
A.2.2. $s_{2}>s_{1}$

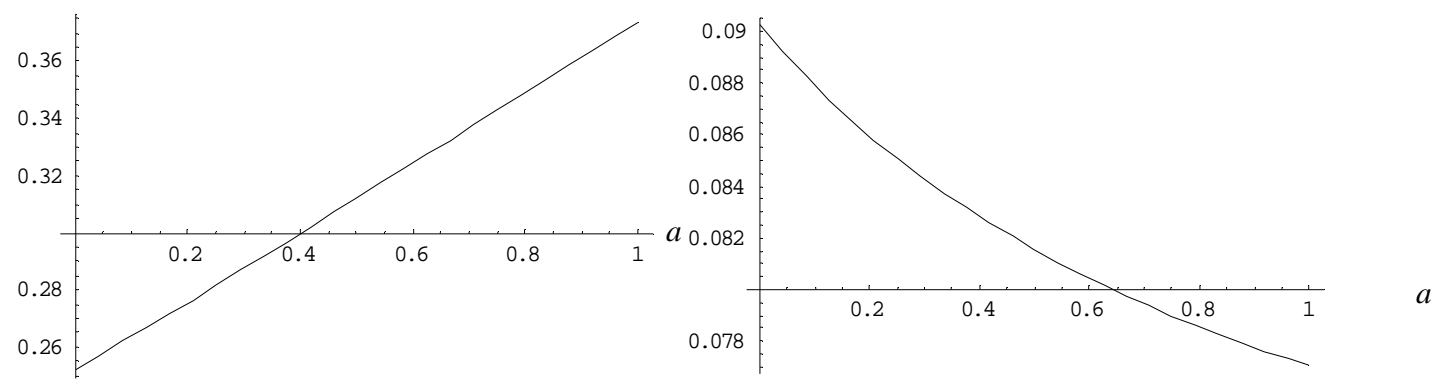

Figure 23: $s_{2}$

Figure 24: $s_{1}$

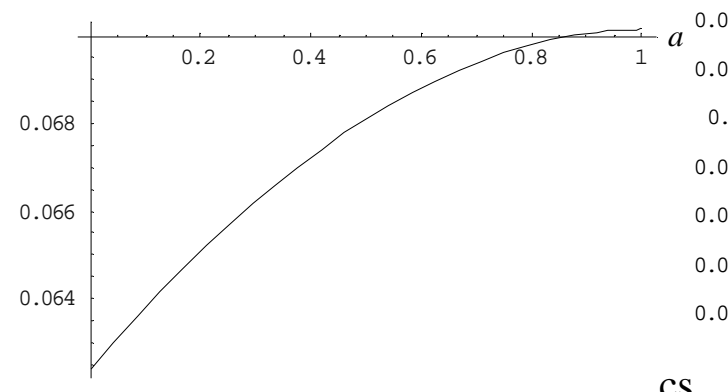

Figure 25: $W$

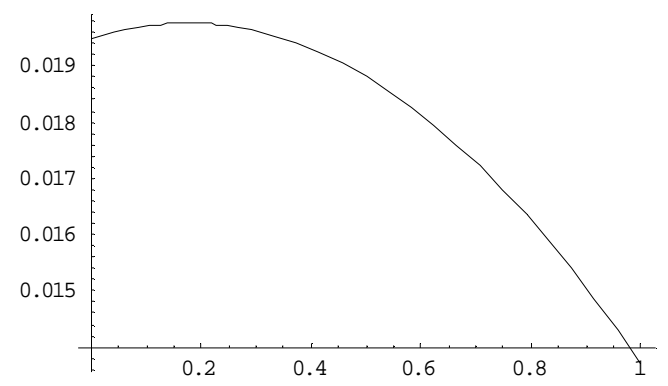

Figure 27: $\Pi_{2}$

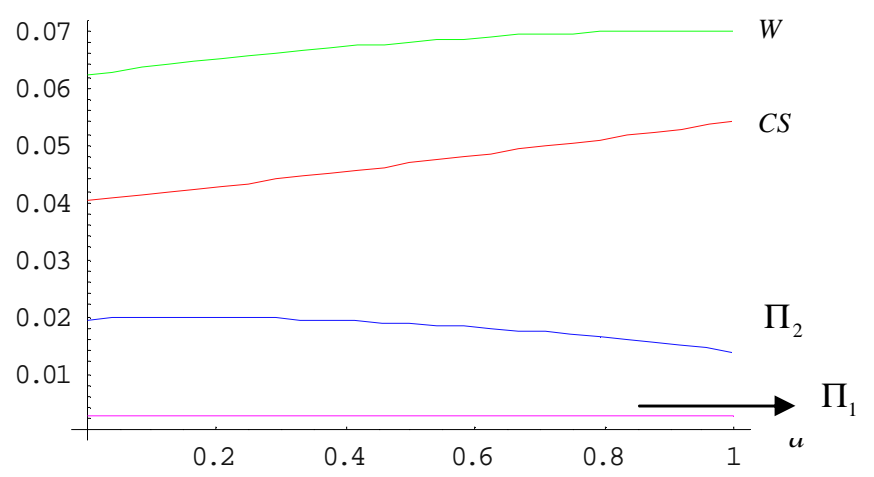

Figure 29

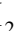

\section{$\Pi_{1}$}

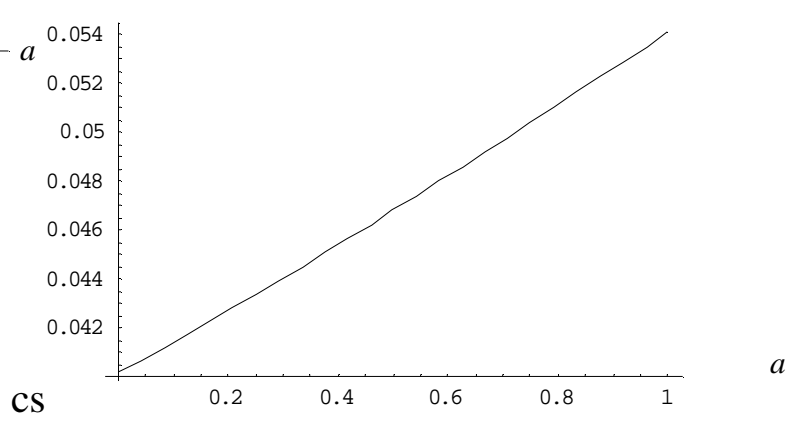

Figure 26: $C S$

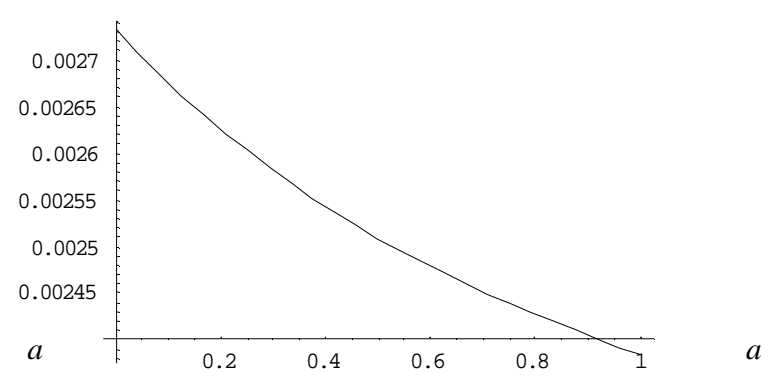

Figure 28: $\Pi_{1}$ 